Neurosurg Focus 7 (6):Article 7, 1999

\title{
Anterior lumbar fusion with titanium threaded and mesh interbody cages
}

\author{
Michael J. Rauzzino, M.D., Christopher I. Shaffrey, M.D., Russ P. Nockels, M.D., Gregory C. Wiggins, M.D., Jack Rock, M.D., and James \\ Wagner, M.D. \\ Departments of Neurosurgery and Surgery, Henry Ford Hospital, Detroit, Michigan; Department of Neurosurgery, University of Washington School of \\ Medicine, Seattle, Washington; and Deptartment of Neurosurgery, Loyola University Medical Center, Maywood, Illinois
}

The authors report their experience with 42 patients in whom anterior lumbar fusion was performed using titanium cages as a versatile adjunct to treat a wide variety of spinal deformity and pathological conditions. These conditions included congenital, degenerative, iatrogenic, infectious, traumatic, and malignant disorders of the thoracolumbar spine. Fusion rates and complications are compared with data previously reported in the literature.

Between July 1996 and July 1999 the senior authors (C.I.S., R.P.N., and M.J.R.) treated 42 patients by means of a transabdominal extraperitoneal (13 cases) or an anterolateral extraperitoneal approach (29 cases), 51 vertebral levels were fused using titanium cages packed with autologous bone. All vertebrectomies ( 27 cases) were reconstructed using a Miami Moss titanium mesh cage and Kaneda instrumentation. Interbody fusion (15 cases) was performed with either the BAK titanium threaded interbody cage (in 13 patients) or a Miami Moss titanium mesh cage (in two patients). The average follow-up period was 14.3 months. Seventeen patients had sustained a thoracolumbar burst fracture, 12 patients presented with degenerative spinal disorders, six with metastatic tumor, four with spinal deformity (one congenital and three iatrogenic), and three patients presented with spinal infections. In five patients anterior lumbar interbody fusion (ALIF) was supplemented with posterior segmental fixation at the time of the initial procedure. Of the 51 vertebral levels treated, solid arthrodesis was achieved in 49, a $96 \%$ fusion rate. One case of pseudarthrosis occurred in the group treated with BAK cages; the diagnosis was made based on the patient's continued mechanical back pain after undergoing L4--5 ALIF. The patient was treated with supplemental posterior fixation, and successful fusion occurred uneventfully with resolution of her back pain. In the group in which vertebrectomy was performed there was one case of fusion failure in a patient with metastatic breast cancer who had undergone an L-3 corpectomy with placement of a mesh cage. Although her back pain was immediately resolved, she died of systemic disease 3 months after surgery and before fusion could occur.

Complications related to the anterior approach included two vascular injuries (two left common iliac vein lacerations); one injury to the sympathetic plexus; one case of superficial phlebitis; two cases of prolonged ileus (greater than 48 hours postoperatively); one anterior femoral cutaneous nerve palsy; and one superficial wound infection. No deaths were directly related to the surgical procedure. There were no cases of dural laceration and no nerve root injury. There were no cases of deep venous thrombosis, pulmonary embolus, retrograde ejaculation, abdominal hernia, bowel or ureteral injury, or deep wound infection. Fusion-related complications included an iliac crest hematoma and prolonged donor-site pain in one patient. There were no complications related to placement or migration of the cages, but there was one case of screw fracture of the Kaneda device that did not require revision.

The authors conclude that anterior lumbar fusion performed using titanium interbody or mesh cages, packed with autologous bone, is an effective, safe method to achieve fusion in a wide variety of pathological conditions of the thoracolumbar spine. The fusion rate of $96 \%$ compares favorably with results reported in the literature. The complication rate mirrors the low morbidity rate associated with the anterior approach. A detailed study of clinical outcomes 
is in progress. Patient selection and strategies for avoiding complication are discussed.

Key Words * anterior lumbar interbody fusion * titanium cage * spinal fusion * complication

Over the last decade an increasing number of neurosurgeons have rediscovered the anterior approach for lumbar spinal fusion. A driving force has been the surgeon's dissatisfaction with surgical outcomes after performing dorsal procedures such as posterior lumbar interbody fusion with pedicle screw instrumentation, particularly in terms of fusion rates and long-term back pain.[7,16,19,34,49,56,58,61] Posterior lumbar interbody fusion has been noted to have high complication rates and lower fusion rates compared with those of the anterior lumbar interbody fusion (ALIF) technique.[19,34,49,56,61] In cases of disc space degeneration/collapse or destructive vertebral body lesions due to trauma, malignancy, or infection, the anterior approach allows biomechanically superior restoration of anterior column height compared with posterior approaches (Figs. 1--4). This restoration of anterior height results in both neural foraminal enlargement and reestablishment of the normal sagittal alignment, resulting in improved clinical outcomes.

Interbody fusion cages have also become increasingly popular as a tool for ALIF, competing with the previously favored autograft and allograft bone. $[40,43,44]$ Cages constructed from various materials and in different shapes are commercially available. Available titanium cages include the threaded interbody cage based on studies by Bagby[1] and mesh cages based on the work of Harms.[17,38] The results of extensive biomechanical testing have demonstrated the strength and resiliency of these cages.[24,36]

\section{CLINICAL MATERIAL AND METHODS}

\section{Patient Selection}

In patients requiring anterior column reconstructive procedures for destructive lesions, the selection criteria were the extent of disease and spinal instability. Consideration was given to the patient's predicted life expectancy in cases of malignancy.

For patients who were being treated primarily for low-back pain the selection process was different. The goal of surgery was cessation or a significant reduction in pain and an improvement in lifestyle. A candid discussion was held with patients to create for them a realistic expectation of outcome. All patients were required to undergo a minimum 6-month course of nonoperative therapies, including alterations in activities, physical therapy, and weight loss or smoking cessation interventions if applicable. Patients with chronic pain syndromes were preoperatively evaluated by our colleagues in the pain clinic for optimization of pain medicines and trials of other treatments, including epidural steroid injections. If all conservative therapies failed and a specific vertebral level or levels was identified as a pain generator, patients were then considered for surgery.

Patients underwent preoperative anteroposterior and lateral radiography, which included obtaining flexion--extension radiographs. Loss of a single disc space height and evidence of instability, as demonstrated on dynamic studies, were useful indicators of a diseased vertebral level. We performed magnetic resonance (MR) imaging to help further confirm the appropriate vertebral level(s). On $\mathrm{T}_{2}$-weighted MR images the presence of bone marrow intensity changes (Modic changes), severe loss of nuclear signal (the "black disc"), severe disc narrowing, and the presence of a high-intensity zone within the posterior annulus were useful indicators of discogenic back pain (Fig. 1 upper left and center).[22,42,51] Magnetic resonance imaging was also used to determine the presence of posterior pathological entities such as disc herniation and lateral recess stenosis in patients with a radicular component to their pain. These patients were then considered for treatment with a posterior technique. 


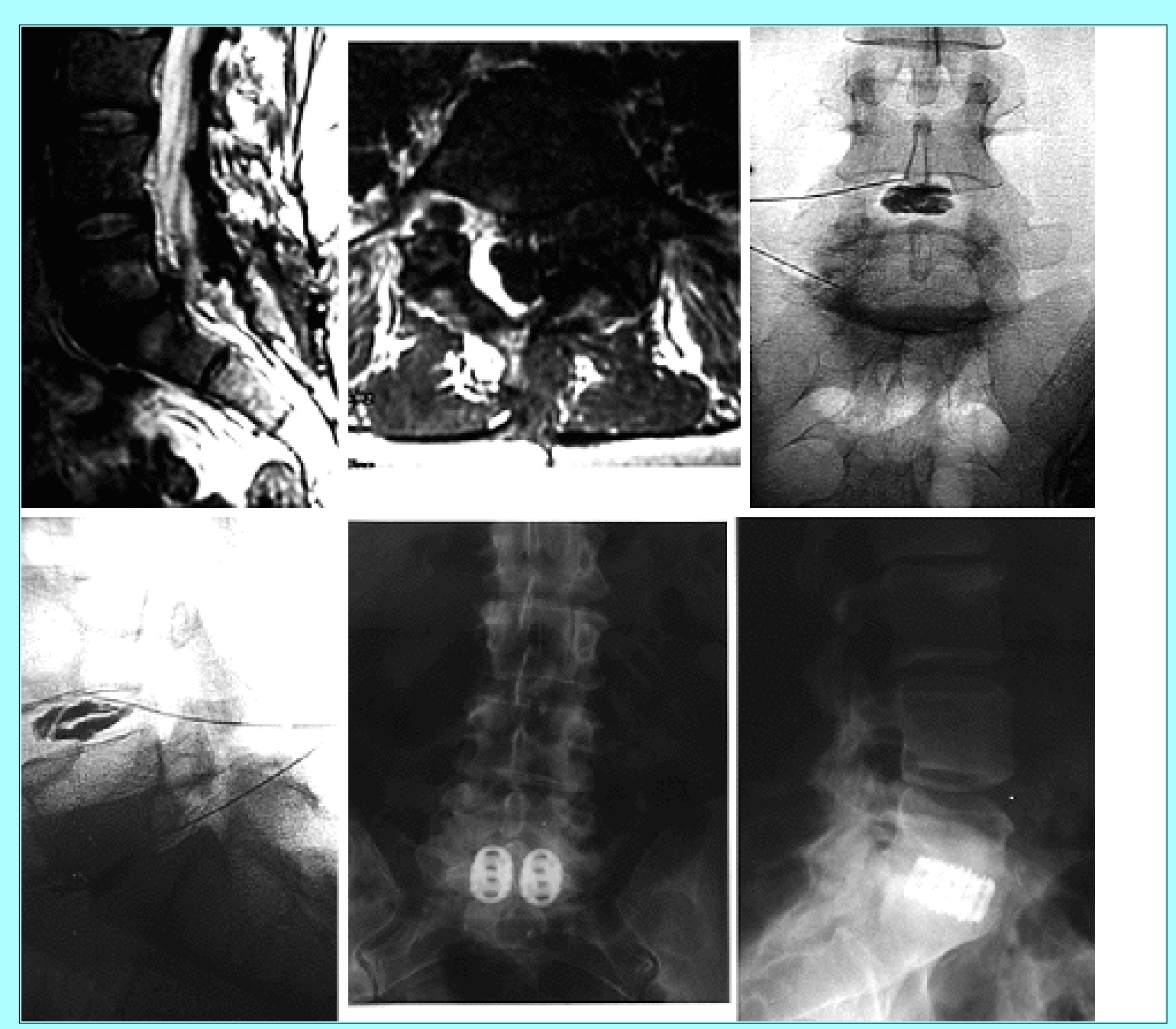

Fig. 1. Imaging studies in a 56-year-old woman who underwent an L5--S1 discectomy and developed recurrent back pain. Sagittal $\mathrm{T}_{2}$-weighted (upper left) and axial (upper center) MR images revealing loss of disc height and previous operative changes. Anteroposterior (upper right) and lateral (lower left) discograms revealing extravasation of contrast at the L5--S1 disc level with reproduction of her pain. Anteroposterior (lower center) and lateral (lower right) radiographs obtained after ALIF in which BAK cage was implanted, demonstrating bridging bone anteriorly (the sentinel sign) and restoration of disc height.

We reserved the use of discography for patients in whom MR imaging findings were inconclusive or in those with more than one diseased vertebral level. A single examiner used a paramedian approach with needles placed at multiple levels. The patient was blinded to the level tested and reported the presence or absence of reproduction of pain during the injection of the contrast material. Pain was graded on a scale of 1 to 10 by the patient. When possible the surgeon was present during the patient's discography. Plain x-ray films and computerized tomography (CT) scans were then obtained to identify patients who had annular and radial tears (Fig. 1 upper right and lower left). 


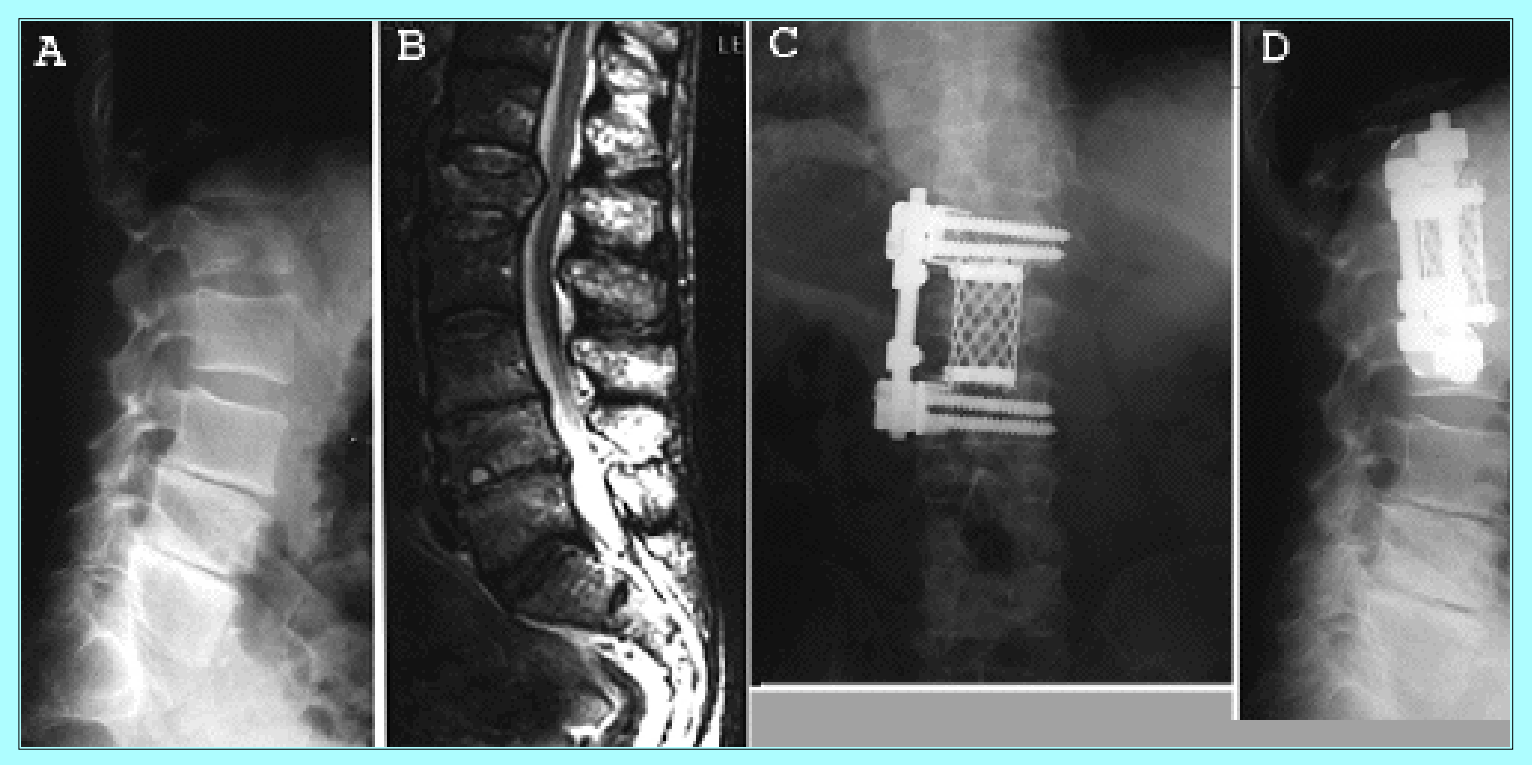

Fig. 2. Imaging studies obtained in a 61-year-old patient who suffered an L-1 burst fracture with incomplete paraplegia after a fall from a height. Lateral radiograph (A) and sagittal $\mathrm{T}_{2}$-weighted MR image (B) revealing the burst fracture and retropulsion into the canal. The patient underwent spinal reconstruction in which an anterior titanium cage and Kaneda construct were used. Postoperative anteroposterior (C) and lateral (D) radiographs demonstrating restoration in the height of the vertebral level and physiological lordosis across the segment.

\section{Surgical Techniques}

The surgical approach to the anterior spinal column was extraperitoneal in all cases and was achieved via a transabdominal or left anterolateral approach. The surgical anatomy for each of these approaches has been well documented.[3,5,6,8,9,35,60] Our exposures are routinely performed by a fellowship trained general surgeon (J.C.W.) who has extensive experience with these approaches. Certain technical points can be stressed. We typically used the transabdominal approach to perform interspace arthrodesis at L3--4 or below. For levels above this level we performed an anterolateral approach and inserted the cages laterally into the disc space. For vertebrectomies we inserted mesh cages via a left anterolateral approach.

\section{Transabdominal Extraperitoneal Approach}

For the transabdominal approach, our incision was either transverse or paramedian, depending on the sex of the patient and the level to be fused. Fluoroscopy was used preoperatively to guide the incision and allow for a correct angle by which to approach the interspace. It is important to place a support under the lumbar spine to exaggerate lordosis and allow the cages to be further compressed at the end of the procedure. Care was taken to identify and mobilize the ureter medially with the peritoneum. The surgical retractor was provisionally placed, and a blunt dissection of the vascular structures was performed. The vessels themselves were retracted using a hand-held retractor. The amount of vascular dissection depended on the level(s) to be fused. At the L3--4 level the iliac vessels were reasonably easy to mobilize and were moved from left to right. At L4--5, one encounters two important venous structures: the left common iliac vein, which crosses the interspace, and the left iliolumbar vein, which may drain into either the common iliac vein or the inferior vena cava. The mobilization of the left common iliac vein was performed bluntly, and it is during this step that the majority of vascular injuries occur. The iliolumbar vein must first be identified and ligated, or it may be avulsed from the common iliac vein during its mobilization. At L5--S1, the approach was somewhat easier because the vessels have typically bifurcated and do not need to be mobilized. A middle sacral vein may be present at this level and, if present, was ligated during the exposure. The midline was identified and marked using anteroposterior fluoroscopy. The surgical retractor was finally tightened and the location of the vessels was always checked prior to placement of the instrument guide and preparation of the bone for cage placement. 
Total en bloc discectomy was not performed. We removed the disc in the space where the cages themselves were inserted and then removed most of the disc material anterior to them to allow us to pack a great deal of bone in front of the cages. We believe in the dictum of "ream long -- cage short," which places the cage in a posterior location and allows room for anterior bone graft.[40] This allows one to achieve bridging of the bone anterior to the cage, which has been referred to as the "sentinel sign"(Fig. 1 lower right, and Fig. 3).

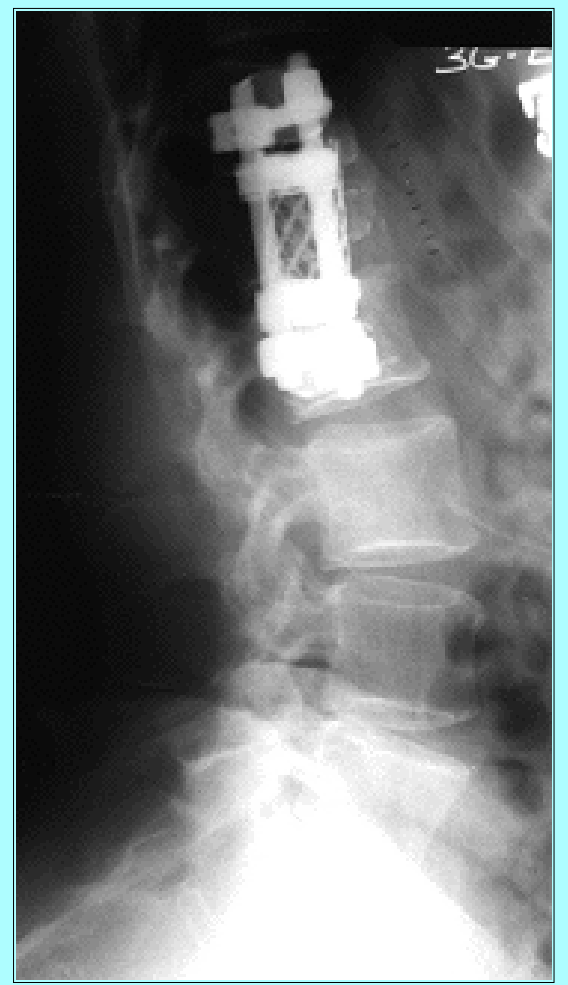

Fig. 3. Two-month postoperative radiograph obtained in a 55-year-old patient who suffered an L-1 burst fracture after a motor vehicle accident, demonstrating the start of the formation of bridging bone anteriorly.

Patients were allowed to ambulate immediately after surgery, and we did not routinely place patients in external orthosis with a single-level threaded cage.

\section{Anterolateral Extraperitoneal Approach}

Our technique for the anterolateral extraperitoneal approach has been recently described.[63] We approached the anterior spine from the left side to avoid manipulation of the vena cava. The patients were carefully positioned in a lateral decubitus position by using a bean bag. Positioning considerations included carefully padding the peripheral nervous system and ensuring that the side on which the fracture occurred was placed over the break of the table. The harvested rib was used for bone graft in addition to the autologous bone obtained from the fractured vertebra or the iliac crest in the cases of malignancy or infection. Once the psoas muscle was exposed, care was taken to avoid injuring the lumbosacral plexus contained within it. Segmental vessels were isolated and ligated. In cases of infection or malignancy, although identification of these vessels was more difficult, they should be sought in the "valley" of the vertebral body where they customarily traverse. Total discectomies were performed and care was taken to preserve the endplates. After the corpectomy and decompressive surgery were performed, the table was completely broken. The Kaneda device (DePuy-Acromed, Cleveland, OH) was applied, and distraction was performed prior to measurement of the cage. The cage, either the BAK titanium interbody cage (Sulzer Spine-Tech, Minneapolis, MN) or the Miami Moss titanium cage (DePuy--AcroMed, Cleveland, $\mathrm{OH}$ ) was packed tightly with autologous bone and tapped into position. The cage was then compressed by releasing the break in the table and compressing the Kaneda device. If the pleural cavity was violated, a red

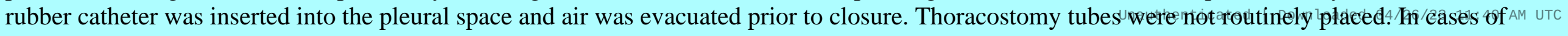


vertebrectomy, however, we routinely placed patients in an external orthosis postoperatively and allowed early mobilization.

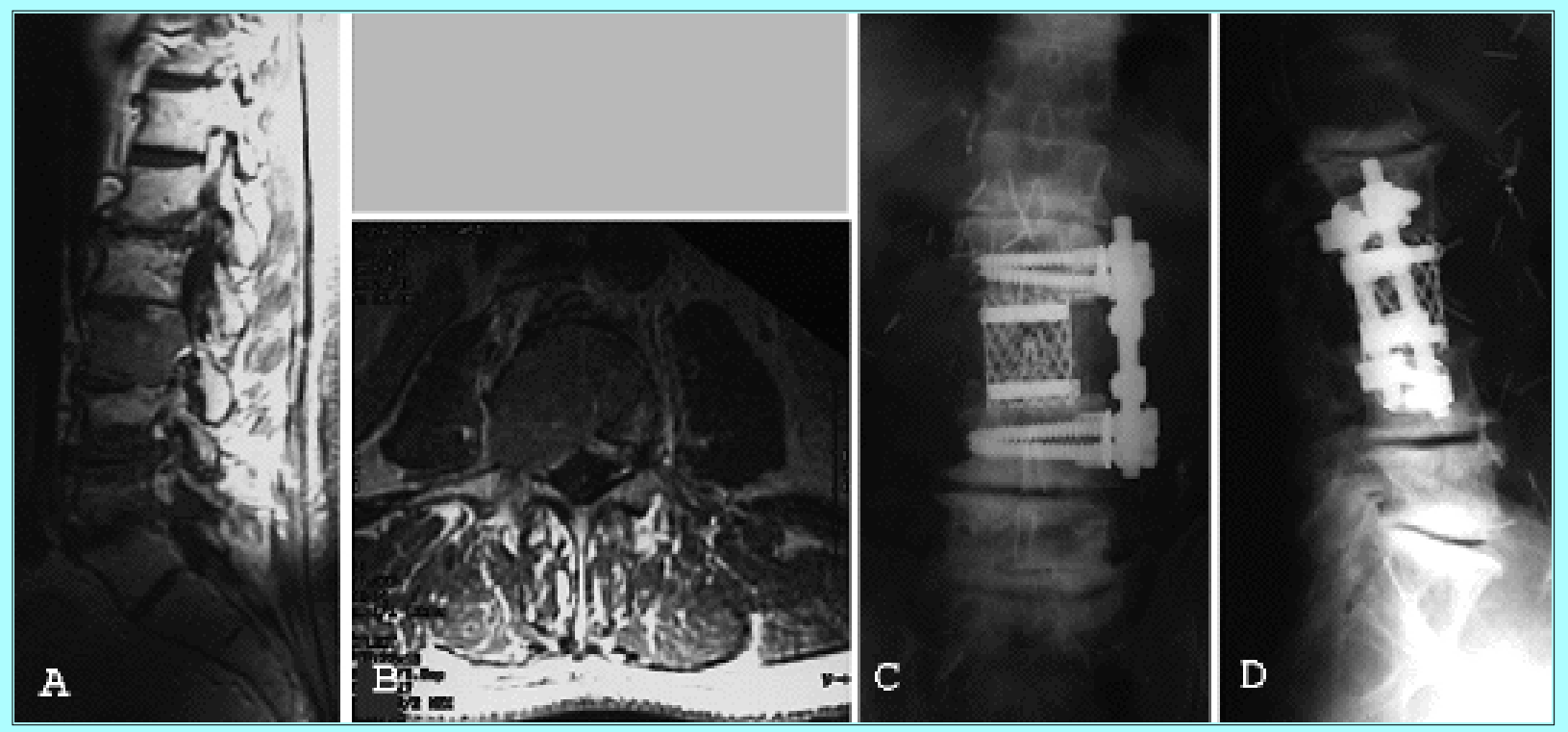

Fig. 4. Imaging studies obtained in a 68-year-old patient with metastatic renal cell carcinoma to the L-3 vertebral body. Sagittal (A) and axial (B) $\mathrm{T}_{1}$-weighted MR images with contrast revealing infiltration through the right L-3 pedicle. The tumor was removed, and the patient underwent spinal reconstruction with an anteriorly placed cage and Kaneda device. Postoperative anteroposterior (C) and lateral (D) radiographs demonstrating maintenance of disc height and lumbar lordosis.

\section{RESULTS}

\section{Fusion Rate}

Table 1 provides a summary of patient data. Of the 51 vertebral levels treated, fusion was achieved in 49 , for a fusion rate of $96 \%$. 
TABLE 1

SUMMARY OF DATA IN 42 PATIENTS WHO UNDERWENT ALIF*

\begin{tabular}{|c|c|c|c|c|c|c|c|c|c|}
\hline $\begin{array}{l}\text { Case } \\
\text { No. }\end{array}$ & $\begin{array}{c}\text { Age (yrs], } \\
\text { Sex }\end{array}$ & Indication & Approach & Fusion Device & $\begin{array}{l}\text { No. of } \\
\text { Levels } \\
\text { Fused }\end{array}$ & Fusion & $\begin{array}{l}\text { Levels } \\
\text { Fused }\end{array}$ & $\begin{array}{l}\text { Supple } \\
\text { mertal } \\
\text { Post } \\
\text { Fusion }\end{array}$ & $\begin{array}{c}\text { Awerage } \\
\text { Follow } \\
U_{p} \\
{[m \infty]} \\
\end{array}$ \\
\hline 1 & $20, M$ & trauma & anterolateral & Miami Moss cage & 1 & yes & $L-1$ & no & 34 \\
\hline 2 & $58, M$ & trauma & anterolateral & Miami Moss cage & 1 & yes & L-2 & no & 32 \\
\hline 3 & $23, M$ & trauma & anterolateral & Miami Moss cage & 1 & yes & $L-1$ & no & 32 \\
\hline 4 & $28, M$ & trauma & anterolateral & Miami Moss cage & 1 & yes & $L-1$ & no & 31 \\
\hline 5 & $23, M$ & trauma & anterolateral & Miami Moss cage & 1 & yes & $L-1$ & no & 30 \\
\hline 6 & $24, M$ & trauma & anterolateral & Miami Moss cage & 1 & yes & $\mathrm{L}-2$ & no & 30 \\
\hline 7 & $70, M$ & trauma & anterolateral & Miami Moss cage & 1 & yes & $L-1$ & no & 23 \\
\hline 8 & $45, M$ & trauma & anterolateral & Miami Moss cage & 1 & yes & $\mathrm{L}-2$ & no & 21 \\
\hline 9 & $45, F$ & tumor & anterolateral & Miami Moss cage & 1 & no & $L-3$ & no & 20 \\
\hline 10 & $34, F$ & tumor & anterolateral & Miami Moss cage & 1 & yes & $\mathrm{L}-1$ & yes & 20 \\
\hline 11 & $43, \mathrm{~F}$ & tumor & anterolateral & Miami Moss cage & 1 & yes & $L-3$ & yes & 20 \\
\hline 12 & $52, M$ & tumor & anterolateral & Miami Moss cage & 1 & yes & $\mathrm{L}-4$ & no & 20 \\
\hline 13 & $45, M$ & trauma & anterolateral & Miami Moss cage & 1 & yes & L-1 & no & 17 \\
\hline 14 & $67, \mathrm{M}$ & tumor & anterolateral & Miami Moss cage & 1 & yes & $L-3$ & no & 16 \\
\hline 15 & $59, M$ & trauma & anterolateral & Miami Moss cage & 1 & yes & L-1 & no & 16 \\
\hline 16 & $43, F$ & trauma & anterolateral & Miami Moss cage & 1 & yes & $L-1$ & no & 15 \\
\hline 17 & $39, \mathrm{M}$ & trauma & anterolateral & Miami Moss cage & 1 & yes & $L-1$ & no & 14 \\
\hline 18 & $39, \mathrm{~F}$ & deformity & anterolateral & Miami Moss cage & 3 & yes & $\begin{array}{l}\text { T12-L1, } \\
\text { L1-L2', } \\
\text { L2-L3 }\end{array}$ & , yes & 13 \\
\hline 29 & $60, M$ & D.JD & transabdominal & anterior BAK & 2 & yes & $\begin{array}{l}\text { L4-L5, } \\
\text { L5-S1 }\end{array}$ & no & 13 \\
\hline 19 & $28, F$ & D.JD & transa.bominal & anterior BAK & 1 & yes & L3-L4 & no & 13 \\
\hline 20 & $38, \mathrm{~F}$ & $\mathrm{D} . \mathrm{JD}$ & transabdominal & anterior BAK & 1 & yes & L5-S1 & no & 13 \\
\hline 21 & $43, M$ & infection & anterolateral & Miami Moss cage & 2 & yes & $\begin{array}{l}\text { L4-L5, } \\
\text { L5-S1 }\end{array}$ & yes & 12 \\
\hline 22 & $45, M$ & trauma & anterolateral & Miami Moss cage & 1 & yes & $\mathrm{L}-1$ & no & 12 \\
\hline 23 & $69, M$ & deformity & anterolateral & lateral BÁK & 2 & yes & $\begin{array}{l}\text { L2-L3 } \\
\text { L3-L4 }\end{array}$ & no & 12 \\
\hline 24 & $49, F$ & D.JD & transabdominal & anterior ВAK & 1 & yes & L5-S1 & no & 10 \\
\hline 25 & $70, M$ & deformity & anterolateral & Miami Moss cage & 2 & yes & $\begin{array}{l}\text { L2-3, } \\
\text { L3-L4 }\end{array}$ & no & 10 \\
\hline 26 & $28, M$ & trauma & anterolateral & Miami Moss cage & 1 & yes & $L-1$ & no & 10 \\
\hline 27 & $48, M$ & D.JD & transabdominal & anterior BAK & 1 & yes & L5-S1 & no & 10 \\
\hline 28 & $70, \mathrm{~F}$ & Infection & anterolateral & Miami Moss cage & 2 & yes & L3-L4 & no & 10 \\
\hline 30 & $51, M$ & tumor & anterolateral & Miami Moss cage & 1 & yes & $\mathrm{L}-2$ & no & 9 \\
\hline 31 & $43, F$ & infection & anterolateral & Miami Moss cage & 1 & yes & $L-1$ & no & 9 \\
\hline 32 & $30, F$ & D.JD & transabdominal & anterior $\mathrm{BAK}$ & 1 & yes & L5-S1 & no & 6 \\
\hline 33 & 26 , M & trauma. & anterolateral & Miami Moss cage & 1 & yes & $L-1$ & no & 6 \\
\hline 34 & $38, \mathrm{~F}$ & deformity & transa.bominal & anterior BAK & 1 & yes & L2-L3 & no & 6 \\
\hline 35 & 49 , M & D.JD & transabdominal & anterior BAK & 2 & yes & $\begin{array}{l}\text { L4-L5, } \\
\text { L5-S1 }\end{array}$ & no & 6 \\
\hline 36 & $35, F$ & D.JD & transabdominal & anterior BAK & 1 & no & L4-L5 & no & 6 \\
\hline 37 & $18, M$ & trauma & anterolateral & Miami Moss cage & 1 & yes & $L-1$ & no & 6 \\
\hline 38 & $65, M$ & D.JD & transabolominal & anterior $\mathrm{BAK}$ & 1 & yes & L5-S1 & no & 5 \\
\hline 39 & $55, M$ & trauma & anterolateral & Miami Moss cage & 1 & yes & $L-1$ & no & 4 \\
\hline 40 & $50, F$ & DJD & transabotominal & anterior BAK & 2 & yes & $\begin{array}{l}\text { L4-L5, } \\
\text { L5-S1 }\end{array}$ & no & 3 \\
\hline 41 & $39, \mathrm{M}$ & D.JD & transa.bdominal & anterior BAK & 1 & yes & L5-S1 & no & 3 \\
\hline 42 & $45, M$ & D.JD & transabdominal & anterior BAK & 1 & yes & L3-L4 & no & 3 \\
\hline
\end{tabular}

* D.JD = degenerati ie joint disease; post = posterior. 
The criteria by which successful fusion was defined were the lack of movement on flexion--extension radiographs and the absence of mechanical back pain. There was one case of pseudarthrosis in the group in which BAK cages were implanted and one case of fusion failure in the group in which vertebrectomy was followed by the placement of the titanium mesh cages. The first case involved a 35-year-old female smoker who underwent an L4--5 ALIF for discogenic disease after two previous lumbar laminectomies for disc herniations. Her 6-month postoperative x-ray films demonstrated no bridging bone, and she experienced continued mechanical back pain despite the absence of gross movement as demonstrated on dynamic studies. She underwent posterolateral fusion in which pedicle screws and autologous bone were used, and her pain was subsequently relieved. Intraoperatively gross movement of the L4--5 segment could be demonstrated prior to the insertion of the pedicle screws. This case highlights the difficulty in assessing a true fusion in the absence of bridging bone anteriorly (Fig. 5).

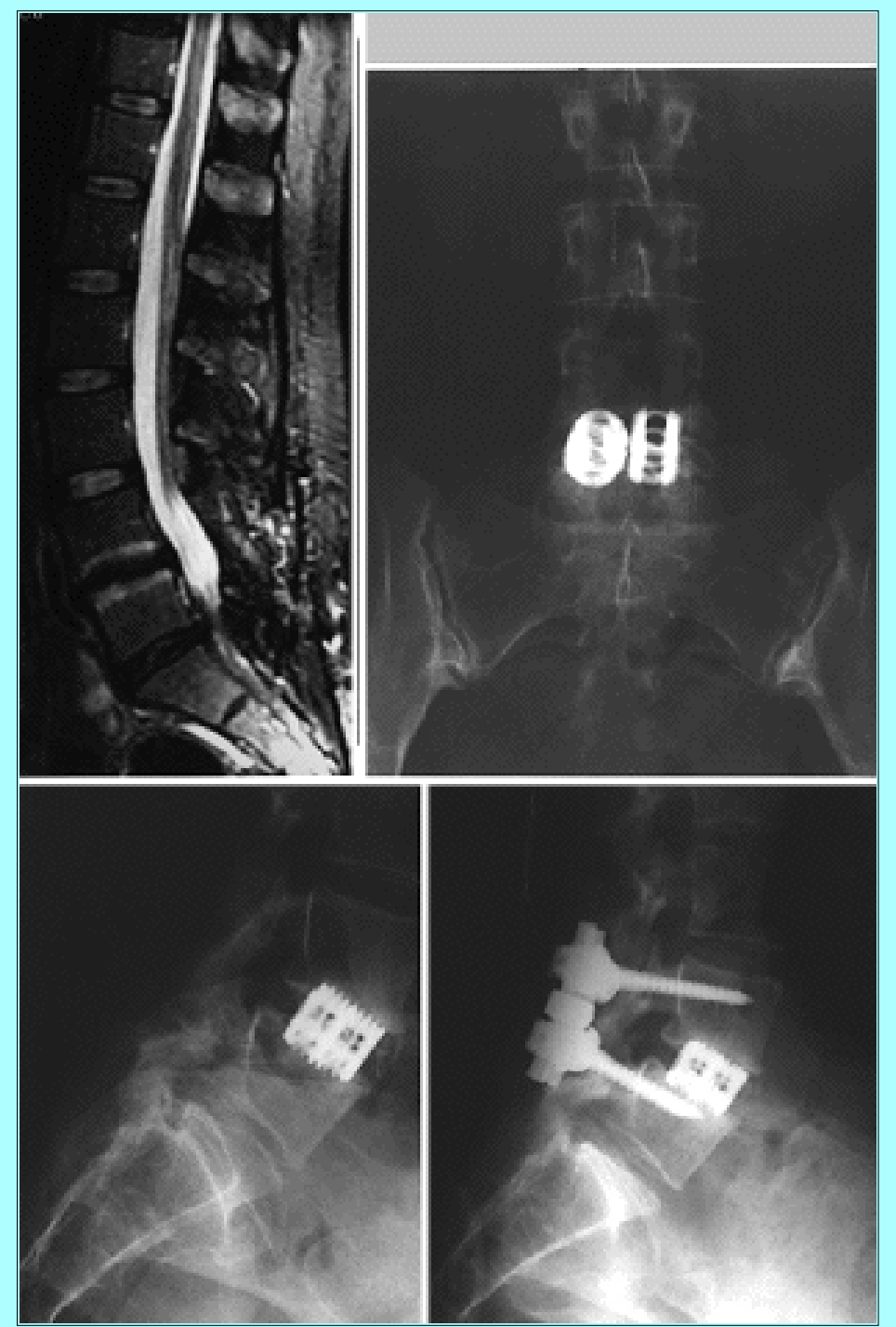

Fig. 5. Imaging studies obtained in a 35-year-old woman who had undergone two previous laminectomies for disc herniations. She continued to experience back pain. Sagittal $\mathrm{T}_{2}$-weighted MR image (upper left) demonstrating modic changes at the L4--5 level. The patient underwent ALIF in which a BAK cage and autologous bone graft were used. Six-month postoperative anteroposterior (upper right) and lateral (lower

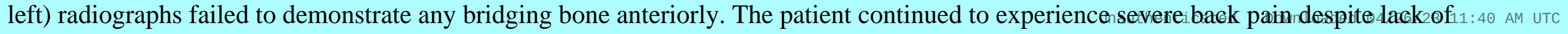


gross movement demonstrated on flexion--extension radiographs. She underwent a posterolateral fusion in which pedicle screw instrumentation and autologous bone graft were placed. An early postoperative lateral radiograph (lower right) failing to demonstrate bridging bone, but the patient's back pain had resolved.

The second case involved a 45-year-old woman with metastatic breast cancer to L-3 who presented with intractable pain and collapse of the vertebrae. She tolerated the vertebrectomy and reconstruction procedure well, and her pain was subsequently relieved, but she succumbed to systemic disease 3 months later before fusion could be radiographically demonstrated.

No other patient failed to achieve arthrodesis with clinical improvement in their pain.

\section{Pain Scores}

Patients' postoperative pain level was rated according to the Denis Pain Scale (Table 2). Pain was rated as P1 or P2 with either no pain or pain that did not require regular medication, respectively, in 34 patients $(81 \%)$. A score of P3 (moderate pain that required medication) was demonstrated in six patients (14\%). A score of P4 or P5 (pain that was severe enough to interfere with their work and normal activities) was determined in two patients, respectively.

\begin{tabular}{|c|c|}
\hline & $\begin{array}{c}\text { TABLE } 2 \\
\text { DEN S PAIN AND WORK SCALES }\end{array}$ \\
\hline Sc ore & Description \\
\hline \multicolumn{2}{|c|}{ pain scale } \\
\hline P1 & no pain \\
\hline $\mathrm{P2}$ & occasional m inimal pain, no need for medication \\
\hline P3 & $\begin{array}{l}\text { moderate pain, occasional medications, no interuption of work or act vities of } \\
\text { daily li wing }\end{array}$ \\
\hline P4 & $\begin{array}{l}\text { moderate to se vere pain, occasional absence from work, significant changes in } \\
\text { activities of daily living }\end{array}$ \\
\hline P5 & constant, se'vere pain, chronic medications \\
\hline \multicolumn{2}{|c|}{ work scale } \\
\hline Wit & return to pre vous em plo yment (heaw/labor) or physically demanding act vities \\
\hline & $\begin{array}{l}\text { able to retum to previous em ployment (sedentary) or retum to heawylabor wh } \\
\text { restrictions }\end{array}$ \\
\hline in 3 & unable to return to previous employment but works full time at new job \\
\hline Wh & unable to return to fulltime work \\
\hline ins & no work, com pletely disabled \\
\hline
\end{tabular}

\section{Work Scores}

Thirty-two of the 42 patients in our series were employed preoperatively. Patients' work outcomes were measured using the Denis Work Scale (Table 2). Twenty-eight (88\%) of these 32 patients were rated either W1 or W2 and were able to return to their previous jobs. Two patients (6\%) were rated W3 and returned to work at different jobs. Two patients (6\%) were rated W4 or W5 and were not able to return to full-time work.

\section{Complications Related to the Anterior Approach}

Vascular Complications. There were two significant vascular complications (4.8\%). Both were tears in the left common iliac vein, occurring at the L4--5 level. One of these venous injuries occurred with the transabdominal approach (7.7\%), and the other venous injury occurred with the anterolateral approach (3.5\%). The first injury occurred early in our series, during a transabdominal approach for a two-level ALIF. While dissecting the left common iliac vein from the L4/5 interspace, a small tear was made in the vessel, which required a suture to close it. Excessive traction on the vessel was thought to be the cause of injury. The second injury was also a tear of the left common iliac vein during an anterolateral approach in a patient with L4--5 
discitis/osteomyelitis and retroperitoneal suppurative inflammation of the subcutaneous connective tissue. He had undergone an anterior approach 2 days earlier with placement of an iliac crest graft that became dislodged and required revision in which the titanium mesh cage was placed. The patient experienced a blood loss of $2000 \mathrm{ml}$ prior to primary closure with multiple sutures. He underwent placement of posterior segmental instrumentation the following week. He remained on a long-term course of intravenous antibiotics, and eventually fusion was achieved. Extensive evaluation confirmed that neither patient developed a venous thrombosis related to the injury.

Venous Thrombosis. There was one case of superficial phlebitis (2.4\%), which occurred 3 days postoperatively in a patient who had undergone an anterolateral approach for treatment of an L-2 burst fracture. There were no cases of deep venous thrombosis or pulmonary embolus in this series.

Sympathetic Plexus Injuries. There was one case of injury to the sympathetic plexus (2.4\%), with the patient noting that the unaffected right foot felt cooler due to the loss of sympathetic vasoconstriction in the affected foot. This injury was noted in the same patient with an L4--5 discitis who had a large retroperitoneal tissue inflammation, which made dissection of anatomical structures difficult. The patient experienced some improvement in symptoms but still noticed the difference 10 months after surgery.

Sexual Dysfunction. There were no cases of sexual dysfunction or complaints of retrograde ejaculation in the 28 male patients involved in the study. It should be noted that we did not perform specific studies to evaluate retrograde ejaculation, and the incidence may be higher than we report.

Nerve Injuries. There was one case of anterior femoral cutaneous nerve palsy (2.4\%) in which the patient noted reduced cutaneous sensation of the anterior portion of the thigh and knee postoperatively after an anterolateral approach for an L-1 burst fracture. This injury was believed to be due to excessive retraction on the psoas muscle with the wide blade retractor. The palsy resolved in the first 6 weeks postoperatively. There were no cases of injury to the nerve roots or other branches of the lumbosacral plexus such as the ilioinguinal or iliohypogastric nerves.

Wound Complications. There was one case of superficial wound dehiscence (2.4\%). The patient was an insulin-dependent diabetic who underwent a transabdominal extraperitoneal approach in which ALIF was performed at L5--S1. The wound was treated with wet-to-dry dressing changes and oral antibiotics. It subsequently healed uneventfully. There were no cases of deep wound infections in our series.

Bowel-Related Injuries. There were no cases of bowel perforation or peritonitis in this series. There were two cases of prolonged ileus (4.8\%) that lasted greater than 48 hours and resolved without requiring nasogastric decompression or other maneuvers. One case occurred after a transabdominal approach and the other after an anterolateral approach.

\section{Complications Related to the Arthrodesis}

Cage-Related Complications. There were no cases of complication during insertion of the cages. There were no cases of cage failure or early or late cage migration. There were no cases of infection of the cages, even in the patients treated for discitis/osteomyelitis. One case of screw fracture of the Kaneda device occurred in a patient who underwent an L-1 vertebrectomy for a burst fracture. The screw fracture was presumed to be related to a subsequent fall and did not require revision because arthrodesis was eventually demonstrated. There were no cases in which hardware prominence of the Kaneda device was an issue.

Complications Related to Bone Graft Harvesting. There was one case in which the patient experienced a postoperative hematoma and prolonged donor-site pain after anterior iliac crest bone graft harvesting was performed. The patient was a very thin woman who underwent a "trap-door" harvest procedure of the anterior iliac crest. She had minimal medullary bone, and the injury was presumed to occur after violation of the posterior cortex, during a vigorous attempt to obtain adequate bone graft. The hematoma occurred in the absence of a surgical drain being placed.

\section{DISCUSSION}

\section{Patient Selection}

The indications for either anterior or posterior interbody fusion continue to evolve. Traditionally, the main indicationtfort ALIFowith 
of cages has been low-back pain. The exact cause of this pain has been unclear. A discogenic cause has been proposed in which it is thought that degenerating intervertebral discs release chemical agents that mediate pain.[14,16,30,55] Segmental instability with resulting abnormal motion has been associated with an increased incidence of low-back pain. In patients with mechanical low-back pain and no overt instability on flexion and extension radiographs, there may be unrecognized micromotion that may be due to rotational destabilization. A radicular component associated with back pain may be attributed to foraminal stenosis due to loss of disc space height.

In the original Food and Drug Administration--approved Investigational Device Exemption Study, the indications for a posterior interbody fusion at a level with the Ray cage included intractable back pain of greater than 1-year duration, severely degenerated disc space, no previous attempts at interbody fusion, an absence of degeneration at adjacent disc spaces, and Meyerding Grade 0 or 1 spondylolisthesis.[48] For the multicenter BAK cage study in which both anterior and posterior interbody fusion were evaluated, the indications were similar but less restrictive. Back pain of 6 months' duration and disease at two or fewer vertebral levels were indications included in this study.[30] Of concern is the trend toward even less restrictive criteria as the use of cages to achieve interbody fusion becomes more popular. In the original protocols, "confirmatory studies" of symptomatic disease were required, but no specific regimen was described. Interestingly, the two more common tools now being used to select patients, signal changes of discs on MR imaging (the so-called black disc) and discography, were not directly mentioned as selection criteria in the original studies.

Although there are relatively few contraindications for using these cages in the anterior technique, severely osteoporotic bone that will not support a structural graft is perhaps the only absolute contraindication.[15,30] It has been reported that active infection and malignancy are contraindications, but we find the use of the anterior technique with the titanium interbody devices to be effective in patients suffering from these conditions (Fig. 4).[3,30,63] Men of reproductive age may find the risk of retrograde ejaculation a contraindication to the anterior approach. Patients with large disc herniations or lateral recess stenosis causing nerve root compression and radiculopathy are best suited to the posterior approach. Rarer contraindications include patients with infrarenal aortic aneurysms, urinary tract abnormalities (that is, a single ureter), and pregnancy. Previous retroperitoneal surgery, infection, or radiation therapy may be considered as relative contraindications to the approach.[30,40,41]

Certain conditions should also be recognized that preclude a solely anterior approach. High-grade spondylolisthesis (Meyerding Grade 3 or greater) is best treated using a combined anterior--posterior approach. Patients with circumferential three-column destructive lesions caused by malignancy or infection may also require a combined approach. Finally, patients with large deformities such as idiopathic or adult scoliosis with large, stiff curves may require a combined approach.[47]

\section{Comparison of Fusion Rates}

The significance of radiographically demonstrated fusion in relation to clinical outcomes is not completely defined. A number of authors have found no association between solid bony fusion and clinical outcomes,[10,11,15] whereas others have found the reverse to be true.[6,12,25,30,35]

An attempt to compare clinical studies of anterior lumbar fusion in terms of fusion rates is difficult because of the different definitions of successful fusion. The rates of fusion appear to be higher when loss of movement on lateral flexion and extension radiographs is the sole criteria for arthrodesis. If fusion is determined by continuous trabeculae across the graft/vertebra interface, the rates of fusion are lower. Because fusion rates in the original studies on cages continued to change for up to 3 years, it is important to follow patients for an appropriate length of time.[25] Some authors propose a complete absence of motion demonstrated on dynamic radiographs as a criterion for fusion, whereas other studies may accept motion of less than 5 as a successful result.[30] Computerized tomography is also used to assess bone fusion.[53] A cortical ring in the periphery and a cancellous marrow in the center of the CT scan form the "double-ring" sign that may be considered pathognomonic of anatomical interbody fusion.

The use of titanium cages has made the evaluation of fusion even more difficult due to imaging artifacts produced by the implants. The presence of bridging cancellous bone on CT scans has been suggested as a useful measure of fusion, although performing a CT examination in patients at each follow-up visit is not feasible.[30] We have defined successful fusion as the complete absence of motion on flexion--extension radiographs accompanied by a positive clinical outcome. Ideally, the radiographic gold standard for a successful fusion is the presence of copious bridging bone across the disc space. In the initial report on the BAK cage, this bridging bone was noted to occur infrequently despite a "successfuhfusion."[B30] Buyereeessing the cagesc 
and placing copious amounts of autologous bone anterior to the implants we have observed this bridging bone more frequently later in our series.

As seen in Table 3 the rates of fusion achieved using ALIF vary considerably (64--100\%). These studies are skewed by a number of variables: graft composition (autograft or allograft), graft design (iliac crest, cage, or bone dowels), number of levels fused, and the presence or absence of supplemental posterior instrumentation. Our fusion rate of $96 \%$ compares favorably with those reported in large series published by Inoue and colleagues[20] (350 patients, 516 affected levels, 94\% fusion rate) and Kuslich and associates[30] (591 patients, 877 affected levels, 93\% fusion rate).

\begin{tabular}{|c|c|c|c|c|c|c|c|c|c|c|c|c|}
\hline \multicolumn{13}{|c|}{$\begin{array}{c}\text { TABLE } 3 \\
\text { REVIEW OF THE LITERATURE ON CASES OF ALIF }\end{array}$} \\
\hline Authors \& Year & $\begin{array}{l}\text { No. of } \\
\text { Patients }\end{array}$ & $\begin{array}{l}\text { No. of } \\
\text { Levels }\end{array}$ & $\begin{array}{l}\text { Men } \\
(\%)\end{array}$ & $\begin{array}{c}\text { Women } \\
(\%)\end{array}$ & $\begin{array}{l}\text { Age } \\
\text { Range } \\
\text { (yts] }\end{array}$ & $\begin{array}{c}\text { Age } \\
\text { Mean } \\
(y+s]\end{array}$ & $\begin{array}{l}\text { Fusion } \\
(\%)\end{array}$ & $\begin{array}{l}\text { Radio- } \\
\text { graphic } \\
\text { Tectnique }\end{array}$ & ALF Graft & $\begin{array}{l}\text { Other } \\
\text { Fixation }\end{array}$ & $\begin{array}{l}\text { Follow } \\
U_{p}\end{array}$ & Notes \\
\hline $\begin{array}{l}\text { Stauffer \& Cowentry, } \\
1972\end{array}$ & 68 & 126 & 44 & 56 & $20-59$ & 42 & 64 & F-E x-ray & $\begin{array}{c}75 \text { auto-iliac, } \\
6 \text { fibula, } 1 \\
\text { tibia, } 1 \text { rib }\end{array}$ & & $=4 y r s$ & \\
\hline $\begin{array}{l}\text { Flynn \& Hogue, } \\
1979\end{array}$ & 50 & 90 & NÁ & NA & NÁ & NÁ & 67 & $x+a y$ & $\begin{array}{l}23 \text { auto-iliac, } \\
27 \text { fitula. }\end{array}$ & & $>2$ yrs & \\
\hline $\begin{array}{l}\text { Chow, et al., } 1980 \\
\text { Fujimaki, et al., } 1982 \\
\text { Leong et al. } 1983\end{array}$ & $\begin{array}{r}97 \\
150 \\
40\end{array}$ & $\begin{array}{r}119 \\
188 \\
63\end{array}$ & 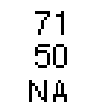 & $\begin{array}{r}29 \\
50 \\
\text { NA }\end{array}$ & $\underset{19-62}{N A}$ & $\begin{array}{r}43 \\
42 \\
\mathrm{~N}\end{array}$ & $\begin{array}{l}63 \\
96 \\
66\end{array}$ & $\begin{array}{l}\text { F-E x-ray } \\
\text { xray } \\
\text { F-E y-ray }\end{array}$ & $\begin{array}{l}\text { auto-iliac } \\
\text { auto-iliac } \\
\text { auto-iliac }\end{array}$ & & $\begin{array}{l}20 \text { yrs } \\
\text { NA }\end{array}$ & \\
\hline & & & & & & & & & auto-iliac & & $\operatorname{ang} 12$ yrs & $\begin{array}{l}1 \text { le vel } 83 \% \\
2 \text { le vel } 57 \%\end{array}$ \\
\hline $\begin{array}{l}\text { Inoue, et al., } 1984 \\
\text { Loguidice, et al, } 1988\end{array}$ & $\begin{array}{r}350 \\
85\end{array}$ & $\begin{array}{l}516 \\
128\end{array}$ & $\begin{array}{l}79 \\
52\end{array}$ & $\begin{array}{l}21 \\
48\end{array}$ & $\begin{array}{l}12-66 \\
21-63\end{array}$ & $\begin{array}{l}31 \\
41\end{array}$ & $\begin{array}{l}94 \\
80\end{array}$ & $\begin{array}{l}\text { xray } \\
\text { F-E } x \text {-ray }\end{array}$ & $\begin{array}{l}\text { auto-iliac } \\
85 \text { auto-iliac, } \\
43 \text { bone domel }\end{array}$ & & $\begin{array}{l}>1 \text { yr } \\
\operatorname{aing} 3 \text { yrs }\end{array}$ & \\
\hline $\begin{array}{l}\text { Knox \& Chapm an, } \\
1993\end{array}$ & 22 & 27 & 23 & 77 & $25-54$ & 40 & 55 & F-E x-ray & auto-iliac & & NÁ & \\
\hline Kum ar, et al., 1993 & 32 & 32 & 66 & 34 & $32-44$ & 38 & 66 & F-E x-ray & allograft & & $>2$ yrs & $\begin{array}{l}88 \% \text { functional } \\
\text { fusion }\end{array}$ \\
\hline Kozak, et al., 1994 & 45 & 53 & NÁ & NA & NA & NA & 84 & $F-E$ xray & allograft & & $>6 \mathrm{mos}$ & $\begin{array}{l}97 \% \text { no move- } \\
\text { ment on } \mathrm{F}-\mathrm{E} \\
\mathrm{xray}\end{array}$ \\
\hline Leong, et al., 1994 & 23 & 26 & 61 & 39 & $13-66$ & 36 & 77 & $F-E x-r a y$ & $\begin{array}{l}\text { titanium mesh } \\
\text { tlock }\end{array}$ & & ang 8 yrs & \\
\hline $\begin{array}{l}\text { Gertzbein, et al., } \\
1996\end{array}$ & 67 & 111 & 54 & 46 & $11-80$ & 44 & 97 & $x+a y$ & $\begin{array}{l}80 \% \text { allograft, } \\
20 \% \text { aut to-liac }\end{array}$ & $\begin{array}{l}\text { PLIF auto- } \\
\text { iliac pedicle } \\
\text { screms }\end{array}$ & $>2$ yrs & \\
\hline $\begin{array}{l}\text { Mahui \& Zdetlick, } \\
1996\end{array}$ & 20 & 21 & 45 & 55 & $31-48$ & 40 & 100 & F-E x-ray & $\begin{array}{l}\text { auto-iliac BAKK } \\
\text { cage }\end{array}$ & & $>6 \mathrm{mos}$ & $\begin{array}{l}\text { laparoscopic, } \\
\text { in } 16 \text { w' x-rase }\end{array}$ \\
\hline $\begin{array}{l}\text { Mathe ws, et al., } \\
1995\end{array}$ & 6 & 6 & 17 & 83 & $35-54$ & 40 & 100 & $F-E$ x-ray & $\begin{array}{l}\text { auto-iliac bone } \\
\text { domels }\end{array}$ & & $>6 \mathrm{mos}$ & laparoscopic \\
\hline Tusanen, et al., & 11 & 11 & 12 & 88 & $10-18$ & 13 & 100 & F-E x-ray & auto-iliac & & aing 4 yrs & \\
\hline $\begin{array}{l}1996 \\
\text { Whang, et al., } 1996\end{array}$ & $\begin{array}{l}16 \\
21\end{array}$ & $\begin{array}{l}16 \\
22\end{array}$ & $\begin{array}{l}31 \\
52\end{array}$ & $\begin{array}{l}69 \\
48\end{array}$ & $\begin{array}{l}12-19 \\
24-42\end{array}$ & $\begin{array}{l}15 \\
34\end{array}$ & $\begin{array}{r}100 \\
95\end{array}$ & $\begin{array}{l}\text { xray } \\
x+a y\end{array}$ & $\begin{array}{l}\text { auto-iliac } \\
\text { auto-iliac } 5 \\
\text { allograft }\end{array}$ & $\begin{array}{l}\text { PLIF auto-iliac } \\
\text { PLIF auto- } \\
\text { iliac pedicle }\end{array}$ & $\begin{array}{l}\text { ang } 5 \text { yrs } \\
\text { ang } 30 \mathrm{mos}\end{array}$ & \\
\hline $\begin{array}{l}\text { Penta \& Fraser, } \\
1997\end{array}$ & 87 & 129 & 42 & 58 & $28-73$ & 48 & $\begin{array}{l}73 \\
83\end{array}$ & $x+a y$ & $\begin{array}{l}60 \text { auto-iliac } \\
65 \text { bone } \\
\text { domels }\end{array}$ & & $>10 \mathrm{yrs}$ & $\begin{array}{c}\text { only } 87 \text { of } 103 \\
w / \text { follo } w \text { up }\end{array}$ \\
\hline
\end{tabular}


TABLE 3, CONTINUED

REVIEW OF THE LITERATURE ON CASES OF ALIF

\begin{tabular}{|c|c|c|c|c|c|c|c|c|c|c|c|c|}
\hline Authors \& Year & $\begin{array}{l}\text { No. of } \\
\text { Patients }\end{array}$ & $\begin{array}{l}\text { No. of } \\
\text { Levels }\end{array}$ & $\begin{array}{l}\text { Men } \\
(\%)\end{array}$ & $\begin{array}{l}\text { Women } \\
{[\%]}\end{array}$ & $\begin{array}{c}\text { Age } \\
\text { Range } \\
\text { (yrs) }\end{array}$ & $\begin{array}{l}\text { Age } \\
\text { Mean } \\
\text { (ys] }\end{array}$ & $\begin{array}{l}\text { Fusion } \\
(\%)\end{array}$ & $\begin{array}{l}\text { Radio- } \\
\text { graphic } \\
\text { Tectmique }\end{array}$ & A.UF Graft & $\begin{array}{l}\text { Other } \\
\text { Fixation }\end{array}$ & $\begin{array}{l}\text { Follow } \\
U_{p}\end{array}$ & Notes \\
\hline $\begin{array}{l}\text { Kuslich, et al., } \\
1998\end{array}$ & 591 & 877 & 54 & 46 & $19-73$ & 42 & 88 & F-E x-ray & auto-iliac BAK & & $>2$ yrs & $\begin{array}{l}\text { at } 12 \operatorname{mos} 93 \% \\
\text { at } 24 \operatorname{mos}\end{array}$ \\
\hline $\begin{array}{l}\text { Lijengwist, et al., } \\
1998\end{array}$ & 41 & 62 & 37 & 63 & $19-59$ & 38 & 95 & $x+a y$ & $\begin{array}{l}\text { allograft with } \\
\text { auto-iliac }\end{array}$ & $\begin{array}{l}\text { transami- } \\
\text { nar sorems }\end{array}$ & ang $30 \mathrm{mos}$ & \\
\hline $\begin{array}{l}\text { Mc Afee, et al., } \\
1998\end{array}$ & 14 & 14 & 64 & 33 & $31-76$ & 53 & 100 & $x+a y$ & $\begin{array}{l}4 \text { bone do wel, } \\
10 \text { auto-iliac }\end{array}$ & & ang $24 \mathrm{mos}$ & $\begin{array}{l}\text { lateral endo- } \\
\text { scopic ap- }\end{array}$ \\
\hline $\begin{array}{l}\text { Vam } \operatorname{tanij} \text {, et al., } \\
1998\end{array}$ & 16 & 25 & 44 & 56 & NA & 38 & 88 & $F-E x$-ray & $\begin{array}{l}\text { auto-iliac BAK } \\
\text { cage }\end{array}$ & $\begin{array}{l}\text { PLF auto- } \\
\text { iliac facet }\end{array}$ & $\operatorname{ang} 4$ yrs & \\
\hline $\begin{array}{l}\text { Whitecloud, et al., } \\
1998\end{array}$ & 35 & 63 & 54 & 46 & $26-76$ & 45 & 79 & xtay & $\begin{array}{l}\text { auto-iliac } \\
\text { Harm's cage }\end{array}$ & $\begin{array}{l}\text { PLF auto- } \\
\text { iliac pedicle } \\
\text { screms }\end{array}$ & $\operatorname{aing} 20 \operatorname{mos}$ & $\begin{array}{l}97 \% \text { if anterior } \\
\text { or posterior } \\
\text { fused }\end{array}$ \\
\hline Kim \& Lee, 1999 & 20 & NA & 40 & 60 & $21-62$ & 44 & 90 & $x+a y$ & $\begin{array}{l}19 \text { autograft } \\
1 \text { allograft }\end{array}$ & & $\operatorname{ang} 4$ yrs & \\
\hline Whimmer, et al., & 39 & 86 & 47 & 53 & $20-65$ & 42 & 92 & $x+a y$ & allograft & $\begin{array}{l}\text { PLF auto- } \\
\text { iliac pedicle } \\
\text { screms }\end{array}$ & $12-24 \mathrm{mos}$ & \\
\hline Whimmer, et al., & 65 & 146 & 47 & 53 & $9-65$ & 40 & 95 & $x+a y$ & autograft & $\begin{array}{l}\text { PLF auto- } \\
\text { iliac pedicle } \\
\text { screms }\end{array}$ & $12-24 \operatorname{mos}$ & \\
\hline present study, & 42 & 52 & 67 & 33 & $18-70$ & 44 & 96 & F-E x-ray & $\begin{array}{l}\text { auto-iliac, } \\
\text { meshiBak } \\
\text { cages }\end{array}$ & $\begin{array}{l}\text { PLF auto- } \\
\text { iliac pedicle } \\
\text { screms }(N=4)\end{array}$ & $14.3 \mathrm{mos}$ & \\
\hline
\end{tabular}

One of the most important factors in increasing the fusion rate is to minimize the number of vertebral levels fused. In a series of 108 consecutive patients undergoing ALIF, Penta and Fraser[45] noted an overall fusion rate of 77.5\%: a $91.3 \%$ fusion rate for one-level fusions and only a 51.2\% fusion rate for multilevel fusions. In the BAK multicenter trial the rate of fusion at 24 months was $98 \%$ for one-level fusions (147 cases) and only $80 \%$ for multilevel fusions (100 cases).[30] In our series no pseudarthrosis was demonstrated in the multilevel group but our number of patients was very small (seven cases).

The question of the ideal bone substrate for interbody fusion remains unanswered. Autogenous bone has been traditionally considered the gold standard. There have been no prospective studies comparing autograft bone with allograft bone for ALIF. In a retrospective study Wimmer, et al.,[64] reported a fusion rate of $97 \%$ for autograft bone (iliac crest) and $92 \%$ for allograft bone (femoral head) in a group of 94 patients who underwent ALIF and posterior fusion with pedicle screws for the treatment of spondylolisthesis. The difference was not statistically significant. Whether this similarity would be seen in stand-alone ALIF cases remains to be answered. As seen in Table 3 reported series in which ALIF is performed using autograft or allograft both achieve a high fusion rate. We currently continue to use autograft bone to pack in our cages, but the development of bone morphogenic proteins may obviate the need for bone harvest.[4,18]

\section{Overall Complications}

Vascular Complications. The most commonly reported complication reported in association with the ALIF technique is vascular injury (range $1--16 \%) .[2,9,10,28,30,47]$ Our overall vascular injury rate of $4.8 \%$ is typical of values reported in the literature, as is the greater incidence of injury in our transabdominal group (7.7\%) compared with the anterolateral group (3.4\%). Baker, et al.,[2] have reported on the incidence of vascular injuries in 102 patients who underwent consecutive anterior lumbar fusion in which the opening procedure was performed by fellowship-trained vascular surgeons. They

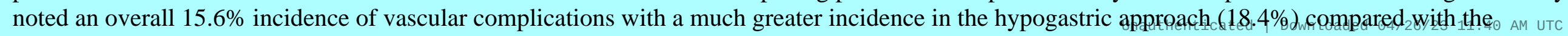


anterolateral approach (7.7\%). In most series, the vessel with the highest rate of injury is the left common iliac vein.[2,9,28,30,46] Vascular injuries almost always occur during the exposure and are usually caused by excessive traction on the vessel. The left common iliac vein is usually found in the bifurcation of the aorta and may appear flat and avascular. It must be identified and retracted prior to cutting the annulus. Injury can be avoided by using a hand-held retractor on the vessel during the exposure. Recognition of the iliolumbar vein is necessary to prevent an avulsion injury during medial dissection of the common iliac. Vessel injuries are controlled by placing direct pressure on the vein and followed by primary repair by using a nonabsorbable suture.

Arterial injury is rarely reported. The left iliac artery is most commonly injured during the anterior approach.[2,47] The aorta and the segmental vessels arising from it are at risk during the anterolateral approach, and its segmental vessels are at risk during the anterolateral approach. The risk of causing paraplegia by ligation of the segmental vessels is minimal. Winter and colleagues[65] have reported a series of 1197 consecutive patients who underwent anterior approaches to the spine for correction of deformity. The exposures required ligation of multiple segmental vessels from T-1 to L-3, and there were no cases in which paraplegia resulted. Vessel ligation is considered safe if the patient remains normotensive and the ligation is unilateral and occurs at the midportion of the vertebral body.

Thromboembolic Complications. The frequency of thromboembolic events after anterior approaches to the spine range from 0 to $12 \% .[2,9,10,28,30,45,46,50]$ Prolonged retraction of large veins and venous injury have been considered risk factors for venous thrombosis. In the study by Baker, et al.,[2] however, a $15.6 \%$ incidence of venous injury translated into only a $0.9 \%$ incidence of deep venous thrombosis and no cases of pulmonary embolus. Rajaraman, et al.,[46] have reported a $1.6 \%$ incidence of deep venous thrombosis and no cases of pulmonary embolus in the 60 consecutive patients who underwent ALIF in which the transabdominal retroperitoneal approach was performed by general surgeons.[47] Measures to avoid thrombus formation include the use of sequential compression devices with stockings and intermittent relaxation of the retractors during the procedure.

One patient $(2.4 \%)$ in our series developed a superficial phlebitis, which resolved within 1 week. There were no cases of deep venous thrombosis or pulmonary embolus in our series.

Sympathetic Nervous System Complications. The reported risk of injury to the sympathetic nervous system during ALIF ranges from 1 to $43 \%$. [6,10,30,46,56] The sympathetic nervous system may be injured during ALIF via the transabdominal or anterolateral approach. Injury to the sympathetic system may clinically manifest postoperatively as retrograde ejaculation in men or by the patient noting that one foot feels colder than the other.

Retrograde ejaculation has been reported to occur in 0.5 to $24 \%$ of men who have undergone ALIF; $[6,10,30,46,56]$ a fair rate of risk to quote to patients ranges from 2 to $5 \%$. The superior hypogastric sympathetic plexus is responsible for bladder neck closure during ejaculation, and injury may result in retrograde ejaculation with the semen expelled into the bladder. The superior hypogastric sympathetic plexus begins anterior to the aorta and continues into pelvis where it may be a plexiform bundle of nerves or single presacral nerve, usually anterior to the L5/S1 disc space. It is therefore particularly at risk during ALIF at the L5--S1 level.[23] Careful blunt dissection and retraction of structures within the bifurcation of the aorta is necessary to avoid injury. The annulus should be incised in a vertical direction. The use of monopolar cautery has been associated with an increased risk of injury to the plexus and should be avoided at this stage of the dissection.[24] Nearly one third of patients who sustain this injury can expect their ejaculate to become prograde within a year.

Injury to the sympathetic trunk may occur in 2 to $43 \%$ of patients who have undergone ALIF. Sympathetic trunk injury results in unregulated vasodilation in the affected leg. $[6,10,30,46,56]$ Typically patients will note the injury in the unaffected leg, observing that it feels cold. The sympathetic chain is at risk for injury during the exposure for both the anterolateral and transabdominal approach. Postoperatively patients may expect some improvement in their symptoms over time.[46]

Nerve Root Injury. Injuries to the nerve roots are uncommon during ALIF. More commonly, injuries occur to the lumbosacral plexus and branches arising from it. The lumbosacral plexus is located in the psoas muscle and is usually damaged from overvigorous retraction on theopsoas 4 during 1 the AM uTC 
exposure or during positioning of the retractors.[21] Flexing the ipsilateral hip during positioning may help to minimize the need for retraction of the psoas and lessen this complication.

Bone Graft--Related Complications. Each BAK cage requires a minimum of $6 \mathrm{ml}$ of cancellous bone to tightly pack it, and in addition we prefer to have copious quantities of additional bone to pack in front of the cages. The surgical techniques for safe harvesting of anterior iliac crest bone graft harvest are well documented.[52] We harvested anterior iliac crest bone graft by using the trap-door technique in all 12 cases in which BAK cages were implanted and in 16 cases in which the mesh cages were used. There was one case of prolonged donor-site pain and hematoma (3.6\%). The complication was caused by aggressive attempts to obtain bone from a thin patient in whom there was a very small iliac crest. The medial cortex was violated and a drain was not placed. In thin patients and in those requiring multilevel cages we have begun harvesting the bone from the posterior iliac crest to provide safe, adequate amounts of bone.

Cage-Related Complications. To date there have been no reported fractures of either a threaded or mesh titanium cage.[40] In our series there were no cases of migration or breakage of the cages. In the multicenter report on the BAK cage by Kuslich and associates[30] there was a less than 1\% incidence of anterior cage migration requiring reoperation. Most cases of implant migration will occur within the first 3 months after surgery and are usually related to the failure to distract the interspace sufficiently and insert an appropriately large cage. Because these cages are increasingly used by a larger number of surgeons, one would expect the reports of complications to rise. This complication can be minimized by a combination of careful preoperative planning so as to size the cage correctly and the surgeon's skill to "feel" the tightness of the cage as it is inserted.

When using the titanium mesh cages for vertebrectomy, cage migration is limited by placing the mesh cage under appropriate compression. This compression is achieved by judiciously using the break in the operating room table to open up the interspace and then by careful distraction followed by compression with the Kaneda device.

There were no cases of infection in patients treated with either the threaded or mesh cages. In the cases in which the mesh cages were used to reconstruct the anterior column in patients with active infection, the infection was cleared and the cages did not act as a nidus for infection.

We have not yet encountered the need to remove a cage. For the titanium mesh cages removal would not be problematic. For the threaded cages this is a potential problem and therefore is a potential disadvantage of their use.

\section{CONCLUSIONS}

The use of titanium threaded or mesh cages has proven to be safe and effective in the management of a wide variety of disorders of the thoracolumbar spine. High fusion rates are attributed to the anterior position of the graft, the use of autologous bone, and placing the graft under compression. The anterior and anterolateral surgical approach to the thoracolumbar spine can be used safely if the surgeon is familiar with the anatomy and is aware of potential complications. Future areas of consideration with the anterior technique and cages include the indications for supplemental posterior fusion and the role of biological adjuncts such as bone morphogenic proteins.

\section{References}

1. Bagby GW: Arthrodesis by the distraction-compression method using a stainless steel implant. Orthopedics 11:931-934, 1988

2. Baker JK, Reardon PR, Reardon MJ, et al: Vascular injury in anterior lumbar surgery. Spine 18:2227-2230, 1993

3. Bhat AL, Lowery GL, Sei A: The use of titanium surgical mesh-bone graft composite in the anterior thoracic or lumbar spine after complete or partial corpectomy. Eur Spine J 8:304-309, 1999

4. Boden SD, Martin GJ Jr, Horton WC, et al: Laparoscopic anterior spinal arthrodesis with rhBMP-2 in a titanium interbody threaded cage. J Spinal Disord 11:95-101, 1998 
5. Calundruccio RA, Benton BF: Anterior lumbar fusion. Clin Orthop 35:63-68, 1964

6. Chow SP, Leong JC, Yaw AC: Anterior spinal fusion or deranged lumbar intervertebral disc: a review of 97 cases. Spine 5:452-458, 1980

7. Cloward RB: The treatment of ruptured lumbar intervertebral discs by vertebral body fusion. I. Indications, operative technique, after care. J Neurosurg 10:154-168, 1953

8. Crock HV: Anterior lumbar interbody fusion: indications for its use and notes on surgical technique. Clin Orthop 165:157-163, 1982

9. Faciszewski T, Winter RB, Lonstein JE, et al: The surgical and medical perioperative complications of anterior spinal fusion surgery in the thoracic and lumbar spine in adults. A review of 1223 procedures. Spine 1995 20:1592-1599, 1995

10. Flynn JC, Hoque A: Anterior fusion of the lumbar spine: end-result study with long-term follow-up. J Bone Joint Surg (Am) 61:1143-1150, 1979

11. Freebody D, Bendall R, Taylor RD: Anterior transperitoneal lumbar fusion. J Bone Joint Surg (Br) 53:617-627, 1971

12. Fujimaki A, Crock HV, Bedbrook GM: The results of 150 anterior lumbar interbody fusion operations performed by two surgeons in Australia. Clin Orthop 165:164-167, 1982

13. Gertzbein SD, Betz R, Clements D, et al: Semirigid instrumentation in the management of lumbar spinal conditions combined with circumferential fusion: a multicenter study. Spine 21:1918-1926, 1996

14. Goldner JL, Urbaniak JR, McCollum DE: Anterior disc excision and interbody spinal fusion for chronic low back pain. Orthop Clin North Am 2:543-568, 1971

15. Greenough CG, Taylor LJ, Faser RD: Anterior lumbar fusion. Results, assessment techniques and prognostic factors. Eur Spine J 3:225-230, 1994

16. Hacker RJ: Comparison of interbody fusion approaches for disabling low back pain. Spine 22:660-665, 1997

17. Harms J: Screw-threaded rod system in spinal fusion surgery. Spine 6:541-545, 1992

18. Hecht BP, Fischgrund JS, Herkowitz HN, et al: The use of recombinant human bone morphogenetic protein 2 (rhBMP-2) to promote spinal fusion in a nonhuman primate anterior interbody fusion model. Spine 24:629-636, 1999

19. Hutter CG: Posterior intervertebral body fusion. A 25-year study. Clin Orthop 179:86-96, 1983

20. Inoue SI, Watanabe T, Hirose A, et al: Anterior diskectomy and interbody fusion for lumbar disc herniation: a review of 350 cases. Clin Orthop 183:22-31, 1984

21. Infantino A, Fardin P, Pirone E, et al: Femoral nerve damage after abdominal rectopexy. Int J Colorectal Dis 9:32-34, 1994

22. Ito M, Incorvaia KM, Yu SF, et al: Predictive signs of discogenic lumbar pain on magnetic resonance imaging with discography correlation. Spine 23:1252-1258, 1998

23. Johnson RM, McGuire EJ: Urogenital complications of anterior approaches to the lumbar spine. Clin Orthop 154:114-118, 1981

24. Jost B, Cripton PA, Lund T, et al: Compressive strength of interbody cages in the lumbar spine: the effect of cage shape, posterior instrumentation and bone density. Eur Spine J 7:132-141, 1998

25. Kant AP, Daum WJ, Dean SM, et al: Evaluation of lumbar spine fusion. Plain radiographs versus direct surgical exploration and observation. Spine 
26. Kim HN, Lee JW: Anterior interbody fusion versus posterolateral fusion with transpedicular fixation for isthmic spondylolisthesis in adults: a comparison of clinical results. Spine 24:812-817, 1999

27. Knox BD, Chapman TM: Anterior lumbar interbody fusion for discogram concordant pain. J Spinal Disord 6:242-244, 1993

28. Kozak JA, Heilman AE, O'Brien JP: Anterior lumbar interbody fusion options: techniques and graft materials. Clin Orthop 300:45-51, 1994

29. Kumar A, Kozak JA, Doherty BJ, et al: Interspace distraction and graft subsidence after anterior lumbar fusion with femoral strut allograft. Spine 18:2393-2400, 1993

30. Kuslich SD, Ulstrom CL, Griffith SL, et al: The Bagby and Kuslich method of lumbar interbody fusion. History, techniques and 2-year follow-up results of a United States prospective, multicenter trial. Spine 23:1267-1278, 1998

31. Leong JCY, Chow SP, Yau AC: Titanium-mesh block replacement of the intervertebral disk. Clin Orthop 300:52-63, 1994

32. Leong JCY, Chun SY, Grange WJ, et al: Long-term results of lumbar intervertebral disc prolapse. Spine 8:793-799, 1983

33. Liljenqvist U, O'Brien JP, Renton P: Simultaneous combined anterior and posterior lumbar fusion with femoral cortical allograft. Eur Spine J 7:125-131, 1988

34. Lin PM: Posterior lumbar interbody fusion technique: complications and pitfalls. Clin Orthop 193:90-102, 1985

35. Loguidice VA, Johnson RG, Guyer RD, et al: Anterior lumbar interbody fusion. Spine 13:366-369, 1988

36. Lund T, Oxland TR, Jost B, et al: Interbody cage stabilization in the lumbar sine: biomechanical evaluation of cage design, posterior instrumentation and bone density. J Bone Joint Surg (Br) 80:351-359, 1998

37. Mahvi DM, Zdeblick TA: A prospective study of laparoscopic spinal fusion. Technique and operative complications. Ann Surg 224:85-90, 1996

38. Majd ME, Vadhva M, Holt RT: Anterior cervical reconstruction using titanium cages with anterior plating. Spine 24:1604-1610, 1999

39. Mathews HH, Evans MT, Molligan HJ, et al: Laparoscopic discectomy with anterior lumbar interbody fusion. A preliminary review. Spine 20:1797-1802, 1995

40. McAffee PC: Interbody fusion cages in reconstructive operations on the spine. J Bone Joint Surg (Am) 81:859-880, 1999

41. McAfee PC, Regan JJ, Geis WP, et al: Minimally invasive anterior retroperitoneal approach to the lumbar spine. Emphasis on the lateral BAK. Spine 23:1476-1484, 1998

42. Modic MT, Steinberg PM, Ross JS, et al: Degenerative disk disease: Assessment of changes in vertebral body marrow with MR imaging. Radiology 166:193-199, 1988

43. Nibu K, Panjabi MM, Oxland T, et al: Multidirectional stabilizing potential of BAK interbody spinal fusion system for anterior surgery. J Spinal Disord 10:357-362, 1997

44. Oda I, Cunningham BW, Abumi K, et al: The stability of reconstruction methods after thoracolumbar total spondylectomy. An in vitro investigation. Spine 24:1634-1648, 1999

45. Penta M, Fraser RD: Anterior lumbar interbody fusion: a minimum 10-year follow-up. Spine 22:2429-2434,u1997icated | Downloaded @4/26/23 11:4๑ AM uTC 
46. Rajaraman V, Vingan R, Roth P, et al: Visceral and vascular complications resulting from anterior lumbar interbody fusion. J Neurosurg (Spine 1) 91:60-64, 1999

47. Rauzzino MJ, Shaffrey CI, Wagner J, et al: Surgical approaches for the management of idiopathic thoracic scoliosis and the indications for the combined anterior-posterior technique. Neurosurg Focus 6 (5):Article 6, 1999

48. Ray CD: Threaded titanium cages for lumbar interbody fusion. Spine 22:667-680, 1997

49. Rish BL: A critique of posterior lumbar interbody fusion: 12 years' experience with 250 patients. Surg Neurol 31:281-289, 1989

50. Sacks S: Anterior interbody fusion of the lumbar spine. Indications and results in 200 cases. Clin Orthop 44:163-170, 1966

51. Schneiderman G, Flannigan B, Kingston S, et al: Magnetic resonance imaging in the diagnosis of disc degeneration: correlation with discography. Spine 12:276-281, 1987

52. Shaffrey CI, Kaptain G, Nockels RP: Bone graft options and harvesting techniques. Tech Neurosurg 3:328-339, 1998

53. Siambanes D, Mather S: Comparison of plain radiographs and CT scans in instrumented posterior lumbar interbody fusion. Orthopedics 21:165-167, 1998

54. Stauffer RN, Coventry MB: Anterior interbody lumbar spine fusion. Analysis of Mayo Clinic series. J Bone Joint Surg (Am) 54:756-768, 1972

55. Tiusanen H, Seitsalo S, Osterman K, et al: Anterior interbody lumbar fusion in severe low back pain. Clin Orthop 324:153-163, 1996

56. Turner JA, Ersek M, Herron L, et al: Patient outcomes after lumbar spinal fusion. JAMA 268:907-911, 1992

57. Vamvanij V, Fredrickson BE, Thorpe JM, et al: Surgical treatment of internal disc disruption: an outcome study of four fusion techniques. J Spinal Disord 11:375-382, 1998

58. Voor MJ, Mehta S, Wang M, et al: Biomechanical evaluation of posterior and anterior lumbar interbody fusion techniques. J Spinal Disord 11:328-334, 1998

59. Wang JM, Kim DJ, Yun YH: Posterior pedicular screw instrumentation and anterior interbody fusion in adult lumbar spondylolysis of grade I spondylolisthesis with segmental instability. J Spinal Disord 9:83-88, 1996

60. Watkins R: Anterior lumbar interbody fusion surgical complications. Clin Orthop 284:47-53, 1992

61. Wetzel FT, Larocca H: The failed posterior lumbar interbody fusion. Spine 16:839-845, 1991

62. Whitecloud TS III, Castro FP, Brinker MR, et al: Degenerative conditions of the lumbar spine treated with intervertebral titanium cages and posterior instrumentation for circumferential fusion. J Spinal Disord 11:479-486, 1998

63. Wiggins GC, Rauzzino MJ, Shaffrey CI, et al: A new technique for the surgical management of unstable thoracolumbar burst fractures: a modification of the anterior approach and an outcome comparison to traditional methods. Neurosurg Focus 7 (1):Article 3, 1999

64. Wimmer C, Krismer M, Gluch H, et al: Autogenic versus allogenic bone grafts in anterior lumbar interbody fusion. Clin Orthop 360:122-126, 1999

65. Winter RB, Lonstein JE, Denis F, et al: Paraplegia resulting from vessel ligation. Spine 21:1232-1234, 1996 
Manuscript received October 18, 1999.

Accepted in final form December 1, 1999.

Address reprint requests to: Michael J. Rauzzino, M.D., Department of Neurosurgery, Henry Ford Hospital, 2799 West Grand Boulevard, Detroit, Michigan 48202. email: Nsmra@neuro.hfh.edu. 